\title{
Development of a peer support intervention to encourage dietary behaviour change towards a Mediterranean diet in adults at high cardiovascular risk
}

Claire T. McEvoy ${ }^{1 *}$ D, Sarah E. Moore ${ }^{1}$, Katherine M. Appleton², Margaret E. Cupples ${ }^{1,3}$, Christina Erwin?', Frank Kee ${ }^{1,3}$, Lindsay Prior ${ }^{3}$, lan S. Young ${ }^{1,3}$, Michelle C. McKinley ${ }^{1,3}$ and Jayne V. Woodside ${ }^{1,3}$

\begin{abstract}
Background: Mediterranean diet (MD) interventions are demonstrated to significantly reduce cardiovascular disease (CVD) risk but are typically resource intensive and delivered by health professionals. There is considerable interest to develop interventions that target sustained dietary behaviour change and that are feasible to scale-up for wider public health benefit. The aim of this paper is to describe the process used to develop a peer support intervention to encourage dietary behaviour change towards a MD in non-Mediterranean adults at high CVD risk.

Methods: The Medical Research Council (MRC) and Behaviour Change Wheel (BCW) frameworks and the COM-B (Capability, Opportunity, Motivation, Behaviour) theoretical model were used to guide the intervention development process. We used a combination of evidence synthesis and qualitative research with the target population, health professionals, and community health personnel to develop the intervention over three main stages: (1) we identified the evidence base and selected dietary behaviours that needed to change, (2) we developed a theoretical basis for how the intervention might encourage behaviour change towards a MD and selected intervention functions that could drive the desired MD behaviour change, and (3) we defined the intervention content and modelled outcomes.

Results: A theory-based, culturally tailored, peer support intervention was developed to specifically target behaviour change towards a MD in the target population. The intervention was a group-based program delivered by trained peer volunteers over 12-months, and incorporated strategies to enhance social support, self-efficacy, problem-solving, knowledge, and attitudes to address identified barriers to adopting a MD from the COM-B analysis.

Conclusions: The MRC and BCW frameworks provided a systematic and complementary process for development of a theory-based peer support intervention to encourage dietary behaviour change towards a MD in non-Mediterranean adults at high CVD risk. The next step is to evaluate feasibility, acceptability, and diet behaviour change outcomes in response to the peer support intervention (change towards a MD and nutrient biomarkers) using a randomized controlled trial design.
\end{abstract}

Keywords: Mediterranean diet, peer support, behaviour change wheel, interventiondevelopment

\footnotetext{
* Correspondence: c.mcevoy@qub.ac.uk

${ }^{1}$ Centre for Public Health, Queen's University Belfast, Grosvenor Road, Belfast BT12 6BJ, UK

Full list of author information is available at the end of the article
}

(c) The Author(s). 2018 Open Access This article is distributed under the terms of the Creative Commons Attribution 4.0 International License (http://creativecommons.org/licenses/by/4.0/), which permits unrestricted use, distribution, and reproduction in any medium, provided you give appropriate credit to the original author(s) and the source, provide a link to the Creative Commons license, and indicate if changes were made. The Creative Commons Public Domain Dedication waiver (http://creativecommons.org/publicdomain/zero/1.0/) applies to the data made available in this article, unless otherwise stated. 


\section{Background}

Cardiovascular disease (CVD) and type 2 diabetes (T2DM) are major public health concerns. Risk of these diseases can be significantly reduced by modifying lifestyle behaviours, such as diet. The Mediterranean diet (MD), rich in fruit, vegetables, wholegrain, nuts, olive oil and oily fish, low in processed foods and moderate in alcohol intake, is rated as the most likely dietary pattern to protect against coronary disease [1] and has been demonstrated, in a randomised controlled trial (RCT) setting, to significantly reduce the risk of developing CVD [2] and T2DM [3]. However, previous interventions to encourage MD behaviour change have used resource intensive methods [2, 3] which may be challenging for some healthcare systems to roll out to an 'at risk' or general population. There is a need to understand how to support dietary behaviour change toward a MD, particularly in non-Mediterranean population (adults living in a non-Mediterranean country), using approaches that are cost-effective, practical and feasible to implement for public health.

Peer support, defined as: 'the provision of emotional, appraisal, and informational assistance by a created social network member who possesses experiential knowledge of a specific behaviour or stressor and similar characteristics as the target population, to address a health-related issue' [4], may offer an alternative method of encouraging dietary change. One RCT, to date, has focused on a peer support behaviour change intervention promoting the MD. A six-month trial of the Mediterranean Lifestyle Programme demonstrated significant improvements in dietary behaviour and glycaemic control in postmenopausal women with existing diabetes [5]. This intervention targeted several health behaviours, including diet, physical activity, smoking and stress, and was delivered using a combination of peer and health professional support strategies. To our knowledge, there are no RCTs examining the effectiveness of exclusive peer-led support on adoption of a MD.

Dietary behaviour is complex and influenced by many factors interacting at psychological, social and environmental levels [6, 7]. Complex interventions aimed at changing behaviour often contain a number of components that can act independently and inter-dependently [8]. To date, there is limited evidence of the effectiveness of dietary interventions for sustained behaviour change [9] which may, in part, be attributable to inadequate intervention design [10]. There is a need to better understand how dietary interventions work, for whom, and in what context, to enable reproducibility of interventions and allow for effective translation of research into public health policy.

Designing a dietary behaviour intervention is a process that requires planning [11]. The most recent Medical Research Council (MRC) framework [11] provides guidance for the systematic development and testing of complex health interventions. A phased iterative approach consisting of development, feasibility and piloting, evaluation and implementation, is recommended, and has been applied in the development of complex health interventions across a wide variety of populations and settings [12-16]. The MRC framework advises that intervention design should be based on a theoretical understanding of how an intervention causes behaviour change. This is important as evaluation of theory-based interventions can elucidate reasons why interventions succeed or fail and how they might be optimised for specific populations. However, there is no consensus on the best method(s) to incorporate theory into intervention design.

Numerous frameworks of individual and population behaviour change are available to address the complexities involved in theory-based intervention development, examples include Intervention Mapping [17], Precede-Proceed Planning model [18] and the Behaviour Change Wheel (BCW) [19]. The BCW evolved from a synthesis of 19 behaviour change frameworks and provides a comprehensive approach to aid behaviour change intervention design. The BCW framework is underpinned by the Capability, Opportunity, Motivation, Behaviour (COM-B) model, which argues that for any behaviour to occur there must be: (i) capability to perform the behaviour (people must have the physical or psychological strength to perform the behaviour; e.g., sufficient knowledge and skills), (ii) opportunity for the behaviour to occur (people must have a conducive physical and social environment; e.g. affordable, accessible and socially/culturally acceptable) and, (iii) motivation to do the behaviour (people must have strong motivation which can be reflective (e.g. conscious planning or beliefs about what is good or bad) and/or automatic; (e.g. emotional reactions and reflex responses) [20]. According to this model, successful dietary behaviour change towards a MD in the population will involve changing one or more of these interacting components. Applying COM-B to the early stages of intervention development can help to identify which components need to change in order for the behaviour to occur in the population [20].

This paper summarises the process used to develop a theory-based, culturally-tailored peer support intervention to encourage dietary behaviour change toward a MD. The development process was guided by the MRC and BCW frameworks. The target population for intervention is Non-Mediterranean individuals at high risk of developing a primary CVD event, as greater MD adherence has been previously shown to significantly reduce CVD risk in a similarly high risk Mediterranean population [2].

\section{Methods}

The process used to develop a theory-based, culturally tailored peer support intervention to encourage MD dietary behaviour change is shown in Figure 1. The MRC framework was used as the overarching guide, while the $\mathrm{BCW}$ 


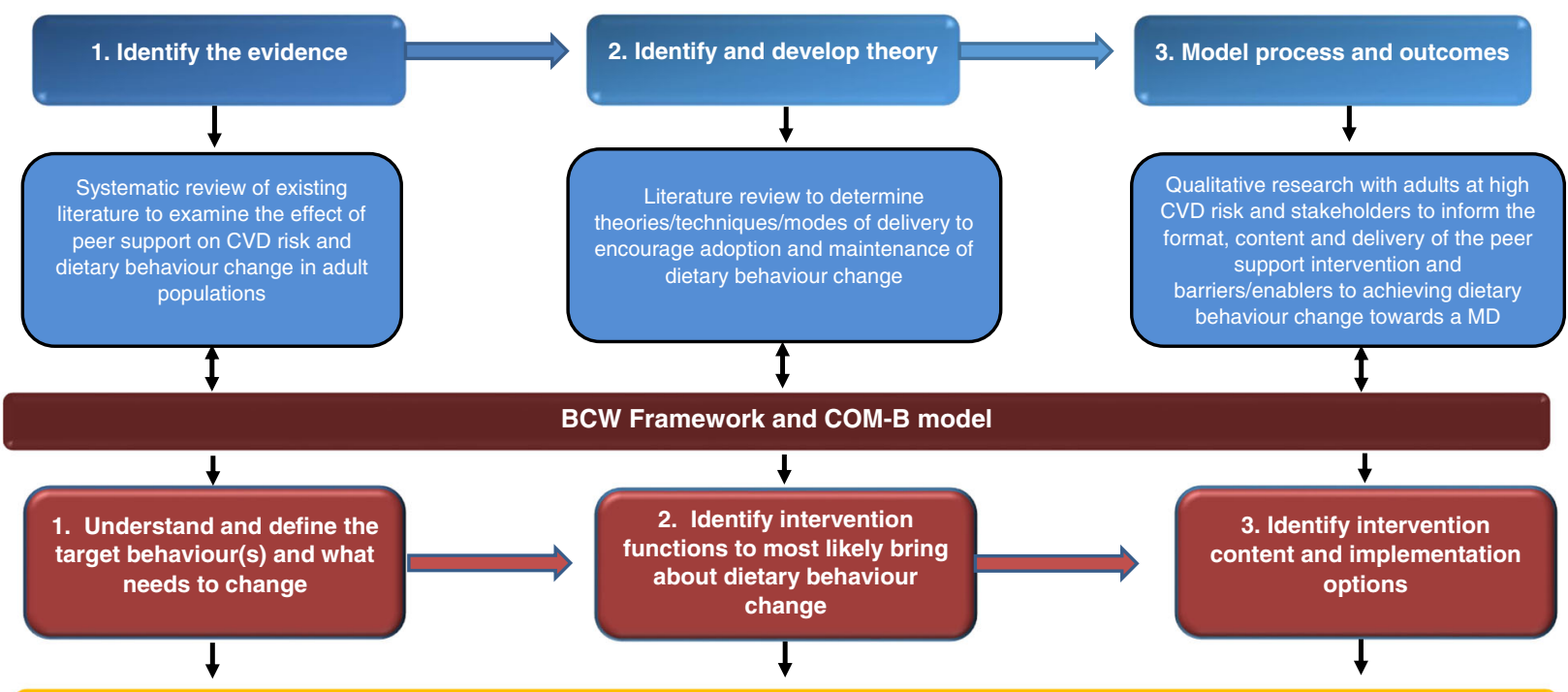

Theory-based, culturally tailored peer support intervention to target individual dietary behaviour change towards a MD

MRC = Medical Research Council; CVD = Cardiovascular Disease Risk; MD = Mediterranean Diet; BCW = Behaviour Change Wheel; COM-B = Capability, Opportunity, Motivation, Behaviour Model

Fig. 1 Process to develop a peer support intervention for dietary behaviour change toward a Mediterranean diet

and COM-B model was applied to define the target behaviours and select the most suitable intervention components (functions and techniques) and implementation approach, based on existing literature and formative work with the target population. Ethical approval for the study was granted by the Health and Social Care, Office for Research Ethics Committees Northern Ireland (reference: $12 / \mathrm{NI} / 0043)$.

There were 3 stages in the peer support intervention development process. The methods used in each stage of the applied MRC and BCW frameworks are described in more detail below.

\section{Stage 1}

\section{MRC Stage 1: Identifying the evidence base}

In this first stage, we reviewed existing literature to identify similar peer support interventions and provide data on outcome and process evaluation methods to inform the development of a peer support intervention to encourage dietary behaviour change in the target population, (see Figure 1).

\section{BCW Stage 1: Understanding and selecting target} dietary behaviours To change dietary behaviour there is a need to understand why behaviours are as they are and what needs to shift for the desired behaviour to occur [21]. Therefore, we reviewed evidence from other RCTs examining MD behaviour change $[2,22]$ to define MD behaviours and to inform the primary outcome assessment of MD behaviour change. In addition, the COM-B model was used to understand dietary behaviour in the context in which it occurs in our target population. We conducted focus group discussions $(n=12)$ with 67 adults (27 male) at high CVD risk, to explore the barriers and enablers to capability, opportunity, and motivation for enacting MD behaviour in a 'real life' individual context. Following iterative focus group analysis, further structured interviews with both the target population $(n=19)$ and a combination of health professionals, community health workers and charity organisation personnel $(n=15)$ were conducted to gain a deeper understanding of the contextual factors influencing $\mathrm{MD}$ behaviour change. We then conducted a COM-B analysis of the qualitative data to determine which theoretical domains need to change for adoption of MD behaviour to occur in the target population.

\section{Stage 2 \\ MRC Stage 2: Developing a theoretical basis for the intervention}

Incorporating theory in the design of behaviour change interventions has been shown to improve effectiveness and can help to elucidate causal pathways of how an intervention works to change health behaviour [11]. In 
stage 2 of intervention development, we identified important psychological theories from existing literature to gain insight into the process of how peer support is likely to change individual dietary behaviour.

BCW Stage 2: Identifying intervention functions most likely to bring about behaviour change towards a MD in the target population The COM-B analysis conducted in $B C W$ Stage 1 above was linked to specific $\mathrm{BCW}$ intervention functions to identify strategies most likely to be effective to facilitate change MD behaviour change in a peer support intervention. The nine $\mathrm{BCW}$ intervention functions to choose from are: education, persuasion, incentivisation, coercion, training, restriction, environmental restructuring, modelling, and enablement [20].

\section{Stage 3}

\section{MRC Stage 3: Modelling processes and outcomes}

In this stage, literature reviews and the views of our target population during stage 1 were used to tailor the peer support intervention appropriately. The focus group discussions with the target population outlined above were also used to determine the preferred peer support mode(s) of delivery. Further individual user preferences (individual ranking of peer support modes of delivery and ratings for peer supporter characteristics) were quantitatively recorded following each focus group discussion.

BCW Stage 3: Identifying intervention content and implementation options $\mathrm{BCW}$ Stage 3 aimed to identify the peer support intervention content in terms of BCTs that would best deliver the identified intervention functions and drive the change in MD behaviour in the population. BCTs are defined as the 'active ingredients' in an intervention designed to bring about change [21], and examples include goal setting, self-monitoring of behaviour and social support. Two trained coders used the Behaviour Change Technique Taxonomy v1 (BCTTv1) [23] and the diet-specific behaviour taxonomy (CALO-RE) [24], to identify the most likely BCTs to effectively deliver the identified intervention functions within the peer support intervention. Identified $\mathrm{BCTs}$ were mapped to theoretical domains identified via the COM-B analysis and literature review.

The overall findings from the tasks performed under the $\mathrm{MRC}$ and $\mathrm{BCW}$ frameworks were synthesised to design the peer support intervention to encourage dietary behaviour change towards a MD in adults at high CVD risk.

\section{Results}

\section{Stage 1}

MRC Stage 1: Identifying the evidence base

Evidence synthesised from literature reviews are discussed in context under the results sections below. In addition, two systematic reviews of published intervention studies were conducted by the research team to examine the effect of peer support on (i) CVD risk (PROSPERO 2014:CRD42014006291) and, (ii) dietary behaviour change (PROSPERO 2014:CRD42014009994) to address gaps in the evidence base. Abstracts of systematic reviews have been submitted and are currently in press.

BCW Stage 1: Understanding and selecting target dietary behaviours From reports of previous RCTs, the $\mathrm{MD}$ was identified as the dietary pattern with the strongest evidence base for CVD prevention [2] and is characterised by a high intake of fruit, vegetables, wholegrains, legumes, nuts and extra-virgin olive oil; a moderate intake of fish and poultry; a low intake of red meat, processed meat and confectionary; and moderate alcohol intake [2]. Hence, there are a range of nutritional behaviours that constitute a MD [25]. Individual MD adherence is determined using a Mediterranean Diet Score (MDS) [2, 22], where the frequency of consumption for a given portion of each specified food component is reported, and MDS is calculated as the sum score for included food components. Several variations of MDS systems are available in different populations, with each MDS comprising a similar ordinal scale (mostly ranging from 9 to 18). A recent meta-analysis reported that a 2-point increase in MDS was associated with a $10 \%$ reduction in CVD incidence and mortality [26]. Furthermore, this degree of MDS increase has been shown to be feasible in a non-Mediterranean population [27]. An evaluation of MD education, delivered by a dietitian, reported a significant increase in MDS (approximately 2-3 points) over 6 months in Northern Irish adults with low baseline MD adherence and pre-existing CVD [28]. Therefore, target behaviour change for the peer support intervention was defined as a $\geq 3$ point increase in MDS from baseline to 6 months (adoption) as this change is likely to be both feasible and clinically important. The dietary behaviours to achieve increase in MDS were based on data from previous MD interventions $[2,22]$ and culturally adapted to incorporate specific food preferences of a non-Mediterranean population as shown in Table 1.

Findings from our focus groups and interviews in relation to barriers for adoption of a MD are reported in full elsewhere [28]. This qualitative work was used to inform the COM-B analysis which identified barriers in capability, opportunity and motivation for achieving dietary change toward a MD in our target population as shown in Table 2.

\section{Stage 2 \\ MRC framework Stage 2: Developing a theoretical basis for the intervention}

Peer support is underpinned by the social support theory defined as 'the process through which social relationships might promote health and well-being' [29]. However, the 
Table 1 Key diet behaviours to assess change towards a Mediterranean diet

\begin{tabular}{|c|c|c|}
\hline \multirow[t]{2}{*}{ Dietary behaviours } & \multicolumn{2}{|l|}{ Targets to determine MD change } \\
\hline & Daily & Weekly \\
\hline Increase Monounsaturated fat (MUFA) & $\begin{array}{l}\text { Olive/rapeseed oils } \geq 4 \text { tblsp }(60 \mathrm{mls}) \\
\text { MUFA-rich spreads } \geq 3 \mathrm{tsp}(15 \mathrm{~g})\end{array}$ & Natural nuts $\geq 3$ handfuls (90g) \\
\hline Increase fruit and vegetables & $\begin{array}{l}\text { Fruits } \geq 2 \text { portions ( } 160 \mathrm{~g}) \\
\text { Vegetables } \geq 3 \text { portions }(240 \mathrm{~g})\end{array}$ & Legumes $\geq 3$ portions ( $240 \mathrm{~g}$ ) \\
\hline Increase wholegrains & $\begin{array}{l}\text { Preferential consumption of wholegrain } \\
\text { cereals over white varieties }\end{array}$ & \\
\hline Increase fish (particularly oily fish) & & Fish $\geq 3$ servings ( $420 \mathrm{~g}$ ) (not battered or crumbed) \\
\hline Reduce meat & & $\begin{array}{l}\text { Red meat } \leq 2 \text { servings }(300 \mathrm{~g}) \\
\text { Processed meat } \leq 1 \text { serving }(150 \mathrm{~g})\end{array}$ \\
\hline Reduce confectionary & & Confectionary $\leq 3$ servings \\
\hline Moderate alcohol & & Alcohol (if consumed) $125-375 \mathrm{ml} \geq 3$ days \\
\hline
\end{tabular}

MDS Mediterranean Diet Score

processes by which peer support can influence health behaviours and outcomes are not fully known and may incorporate two main hypotheses. Firstly, the 'Direct Effect hypothesis' postulates that peer support could reduce feelings of isolation and loneliness, provide information about benefits of behaviours, such as diet, that positively improve health and well-being and encourage adoption and maintenance of new behaviours [4]. Secondly, the 'Buffering Effect hypothesis' suggests that peer support can help people to engage in problem solving and develop and

Table 2 COM-B analysis demonstrating intervention functions and BCTs to change diet in target population

\begin{tabular}{|c|c|c|c|}
\hline $\begin{array}{l}\text { Barriers to adopting a MD in } \\
\text { adults at high CVD risk [28] }\end{array}$ & COM-B analysis & Intervention functions & $\begin{array}{l}\text { BCTs [23] to best serve } \\
\text { intervention functions }\end{array}$ \\
\hline $\begin{array}{l}\text { Lack of knowledge about the types/proportions } \\
\text { of foods consumed }\end{array}$ & Psychological capability & $\begin{array}{l}\text { Education } \\
\text { Training } \\
\text { Enablement }\end{array}$ & $\begin{array}{l}\text { Instruction on how to perform the behaviour } \\
\text { Demonstration of the behaviour }\end{array}$ \\
\hline Limited cooking skills to prepare meals & Physical capability & $\begin{array}{l}\text { Training } \\
\text { Enablement }\end{array}$ & $\begin{array}{l}\text { Instruction on how to perform the behaviour } \\
\text { Behavioural practice } \\
\text { Demonstration of the behaviour }\end{array}$ \\
\hline $\begin{array}{l}\text { Resistance to change eating habits established } \\
\text { since childhood, especially to reduce intake of } \\
\text { red/processed meats and sweet foods }\end{array}$ & Automatic motivation & $\begin{array}{l}\text { Modelling } \\
\text { Persuasion } \\
\text { Enablement }\end{array}$ & $\begin{array}{l}\text { Social support (unspecified) } \\
\text { Problem-solving } \\
\text { Goal setting (behaviour) } \\
\text { Action planning } \\
\text { Feedback on behaviour } \\
\text { Set graded tasks }\end{array}$ \\
\hline $\begin{array}{l}\text { Increased cost for purchasing key foods especially } \\
\text { olive oil, nuts and fruits and vegetables }\end{array}$ & Physical opportunity & $\begin{array}{l}\text { Training } \\
\text { Enablement }\end{array}$ & $\begin{array}{l}\text { Instruction on how to perform the behaviour } \\
\text { Demonstration of the behaviour }\end{array}$ \\
\hline $\begin{array}{l}\text { Increased time to prepare meals owing to busy } \\
\text { lifestyles }\end{array}$ & Physical opportunity & $\begin{array}{l}\text { Training } \\
\text { Enablement }\end{array}$ & $\begin{array}{l}\text { Instruction on how to perform the behaviour } \\
\text { Demonstration of the behaviour }\end{array}$ \\
\hline $\begin{array}{l}\text { Limited availability of fresh foods especially fresh } \\
\text { fish, fruit and vegetables }\end{array}$ & Physical opportunity & $\begin{array}{l}\text { Training } \\
\text { Enablement }\end{array}$ & Instruction on how to perform the behaviour \\
\hline $\begin{array}{l}\text { Lack of understanding about the health benefits } \\
\text { of adopting a MD }\end{array}$ & Psychological capability & $\begin{array}{l}\text { Education } \\
\text { Training } \\
\text { Enablement }\end{array}$ & $\begin{array}{l}\text { Information about health consequences } \\
\text { Biofeedback }\end{array}$ \\
\hline Negative attitude toward increasing total fat intake & Reflective motivation & $\begin{array}{l}\text { Education } \\
\text { Persuasion }\end{array}$ & $\begin{array}{l}\text { Information about health consequences } \\
\text { Instruction on how to perform the behaviour } \\
\text { Demonstration of the behaviour }\end{array}$ \\
\hline $\begin{array}{l}\text { Cold climate making it difficult to eat foods such as } \\
\text { salads, fruit and vegetables }\end{array}$ & Physical opportunity & $\begin{array}{l}\text { Training } \\
\text { Enablement }\end{array}$ & $\begin{array}{l}\text { Social support (unspecified) } \\
\text { Verbal persuasion } \\
\text { Problem-solving }\end{array}$ \\
\hline $\begin{array}{l}\text { Cultural norms making it difficult to change dietary } \\
\text { behaviour }\end{array}$ & Social opportunity & $\begin{array}{l}\text { Modelling } \\
\text { Enablement }\end{array}$ & $\begin{array}{l}\text { Instruction on how to perform the behaviour } \\
\text { Demonstration of the behaviour }\end{array}$ \\
\hline $\begin{array}{l}\text { Negative attitude toward the taste of key foods } \\
\text { especially olive oil, nuts and fish }\end{array}$ & Reflective motivation & $\begin{array}{l}\text { Education } \\
\text { Persuasion }\end{array}$ & $\begin{array}{l}\text { Instruction on how to perform the behaviour } \\
\text { Demonstration of the behaviour Social support } \\
\text { (unspecified) }\end{array}$ \\
\hline
\end{tabular}


strengthen coping mechanisms and self-efficacy to overcome personal barriers, including stress, which may impact on successful behaviour change [4].

We identified Bandura's Social Cognitive Theory (SCT) [30] which has been used successfully to change dietary behaviour in other interventions [31,32] and is a useful theory to inform potential mediating factors involved in dietary behaviour change towards a MD. The SCT acts at the interpersonal level and focuses on the role of observing and learning from others, and on positive and negative reinforcement of behaviour. The key constructs are perceived self-efficacy, outcome expectations, self-regulation and perceived barriers and enablers to enacting the behaviour. These constructs (particularly self-efficacy and self-regulation) have been shown to predict fruit and vegetable intake [31, 32] and fat intake [32, 33], which are also food components of a MD.

In our high CVD risk population, the Health Belief Model (HBM) [34], was also considered important for initiation and maintenance of MD dietary behaviour change at the intrapersonal level. The HBM proposes that successful behavioural change will depend on the individual's perceived susceptibility to the problem, the seriousness of the consequence of the problem, the perceived benefits of making the change and the perceived barriers to making the desired dietary changes.

Many peer support interventions described in the literature do not clearly describe the detail of the behavioural strategies used by peers to support behaviour change [35]. A recent systematic review [36] and a meta-analysis [37] indicated that social support, goal setting and self-monitoring strategies in interventions are associated with improved dietary behaviours. Less is known about effective BCTs for maintenance of newly adopted dietary behaviour; although engaging social support, setting and reviewing dietary goals, self-monitoring and using problem-solving techniques are thought to be important strategies for longer-term maintenance [38, 39].

BCW Stage 2: Intervention functions most likely to bring about behaviour change towards a MD in the target population We found that five of the nine listed $\mathrm{BCW}$ intervention functions were considered most relevant to the COM-B analysis conducted in $B C W$ Stage 1. The five intervention functions were: education (increasing knowledge), persuasion (influencing attitudes and actions), training (imparting skills), modelling (using examples for people to aspire to) and enablement (providing support to overcome barriers) [20], as shown in Table 2. These intervention functions were considered most likely to be effective to elicit MD change in the target high CVD risk population using a peer support approach.

\section{Stage 3}

MRC Stage 3: Modelling processes and outcomes

Previous reviews have highlighted several components of peer support interventions that may impact on overall effectiveness [40-42] and are important to consider in the early stage of intervention development. These components include: the level of intervention dose and content (behavioural content, frequency and duration of peer support), acceptability of the intervention (user preference for peer support mode of delivery and type of support provided; willingness to change dietary behaviour), the characteristics of peer supporters (skills, attributes, availability, flexibility and personal experiences), and the social environment in which the peer support takes place (family setting and the wider community) [4042]. Furthermore, many different peer support approaches are described in interventions, for example, face-to-face group or individual programmes, telephone-based or internet-based peer delivered support or a combination of these approaches, and the effectiveness of each have not been conclusively evaluated [43].

Therefore, the peer support intervention format and content was informed by user preferences that were gathered during focus group discussions with the target population and reported elsewhere [44]. In brief, the target population preferred a group-based mode of peer support delivery, either alone or in combination with face-to-face mentoring or telephone support. Preferences were similar across demographics, including gender and geographical location (urban and rural settings). Meeting face-to-face was considered superior to anonymous 'distance' approaches and believed to help build trust, foster empathy and facilitate the sharing of personal experiences. Meeting as a group was perceived to create greater opportunity for social engagement to learn from others' experiences, and, in this way, help to strengthen individual motivation to change dietary behaviours. In addition, qualitative analyses revealed a number of important factors to shape the context, format and content of a peer support intervention including: context (e.g. preference for a convenient community-based location, and for increased frequency of support initially etc.), format (e.g. preference for non-directive, interactive group sessions, based on discussion and shared experience), and, content (e.g. request for information about MD food components, written materials, recipe ideas, tasting sessions, health measurements etc.) [44].

BCW Stage 3: Identifying intervention content and implementation options The Behaviour Change Technique Taxonomy v1 (BCTTv1) [23] and the diet-specific behaviour taxonomy (CALO-RE) [24], were used to select intervention content in terms of BCTs that would best serve the COM-B analysis and the five selected 
$\mathrm{BCW}$ intervention functions. A total of 12 potential BCTs were identified using the BCTT [23] for inclusion in the peer support intervention, as described in Table 2. Some of the identified BCTs were in agreement with successful dietary behaviour change in previous interventions (goal setting, problem solving, social support, action planning and self-monitoring of behaviour), however, several identified BCTs were specific to supporting individual dietary behaviour change in adults at high CVD risk (instruction and demonstration of the behaviour, information about health consequences, setting graded tasks, verbal persuasion, feedback on behaviour and biofeedback. The CALO-RE taxonomy [24] was used to augment and expand on identified BCTs to ensure a comprehensive evaluation of techniques specific to diet behaviour change. Ten BCTs from the CALO-RE taxonomy were considered important for inclusion in the peer support intervention: provide normative behaviour about others' behaviour, provide information on when and where to perform the behaviour, plan social support/social change, goal setting (outcome), prompt self-monitoring of behaviour, prompt review of behavioural goals, prompt self-monitoring of behavioural outcome, prompt review of behavioural goals, use of follow-up prompts and relapse prevention/coping planning.

A total of 18 BCTs were selected by the research team $(n=4)$ for inclusion in the intervention as shown in Table 3. Selected BCTs were chosen because they were most likely to address COM-B deficits for desired MD

Table 3 Behaviour Change Techniques for peer support intervention to encourage dietary change towards a Mediterranean Diet

\begin{tabular}{ll}
\hline COM-B domain & BCT for inclusion in the intervention $(n=19)$ \\
\hline Capability & $\begin{array}{l}\text { Provide normative behaviour about others' behaviour } \\
\text { Provide instruction on how to perform behaviour }\end{array}$
\end{tabular}
Example of intervention strategy to deliver BCT

Peer supporters provide information about current MD adherence in Northern European populations

Peer supporters provide group members with a booklet and a visual guide (MD food pyramid) to explain the types and proportions of food components in a MD

Model/demonstrate the behaviour Provide information on when and where to perform the behaviour Set graded tasks

Opportunity Plan social support/social change Social support (unspecified)

Motivation Barrier identification/problem solving

Goal setting (behaviour)

Goal setting (outcome)

Action planning

Provide information on consequences of behaviour in general

Biofeedback

Prompt self-monitoring of behaviour

Prompt self-monitoring of behavioural outcome

Prompt review of behavioural goals

Use of follow-up prompts

Relapse prevention/coping planning
Peer supporters show a short video clip to group members demonstrating preparation and consumption of a MD on a budget

Recipe books and written information provide information regarding different meals, and also eating out as well as eating in the home. Increasing adherence to a MD is broken down into smaller tasks within written materials, e.g. food swaps are listed separately for each major MD component

Group members are encouraged to support and contact each other between group sessions

Peer supporters and group members provide positive encouragement and support to each-other to adopt new MD behaviours

Peer supporters facilitate group discussion to identify barriers/ challenges in achieving personal MD goals and assist members to select the best strategies to overcome these

Peer supporters support members to set MD goals at each group session based on the session topic

Group members are encouraged within their personal planners to define what they want to achieve by taking part in the peer support groups, e.g. weight loss, reduce CVD risk etc.

Peer supporters support members to set MD goals that are easy to measure, something that can be achieved, small and meaningful (i.e. SMART goals) at each group session

Peer supporters show a short video clip to group members demonstrating the health effects of a MD

Peer supporters offer individual feedback on blood pressure and weight measurements at each group session

Group members are given personal planners to monitor their daily/weekly progress in achieving set MD goals and to allow them to record any barriers/challenges they experience

Group members are encouraged to log and monitor their weight, blood pressure etc. in personal planners

Each group session will provide an opportunity for general progress review in terms of behaviour

Group sessions decrease in frequency after six months

One group session (session nine) is dedicated to maintenance of dietary change and relapse prevention 
behaviour change, acceptable to the target high CVD risk population and feasible to implement by the research team. Two BCTs were not included (verbal persuasion and feedback on behaviour) as these strategies were not considered compatible with a peer support approach. Hence, capability to increase MDS will be addressed by offering instruction and demonstration of the behaviour (through written educational material, video and group discussion). Opportunity to increase MDS will be enhanced by engaging peer and group social support to encourage dietary behaviour change. Finally, motivation to increase MDS will be facilitated by a cluster of self-regulatory BCT's including problemsolving, goal setting, action planning, self-monitoring, as well as including biofeedback, and information on health consequences, which were important to the target population.

We developed a range of resources to facilitate MD behaviour change in the population and to optimise delivery of selected BCTs in the peer support intervention. Written educational materials and practical resources to provide information on the MD and associated health benefits alongside practical support, such as meal plans, shopping lists, recipe books and self-monitoring resources were developed specifically to target barriers to dietary behaviour change towards a MD in the population [28]. Intervention implementation options were selected from user preferences for the format, content and delivery of peer support as outlined under MRC stage 3 above. Hence, a group-based peer support intervention was selected as the best approach to encourage dietary change towards a MD in adults at high CVD risk.

\section{Description of the resulting theory-based peer support intervention to encourage dietary behaviour change in adults at high CVD risk}

The tasks performed in three stages within the MRC and $\mathrm{BCW}$ frameworks were integrated to develop a tailored, culturally acceptable and theory-based peer support intervention to encourage dietary behaviour change towards a MD. The overall aim of the developed peer support intervention was to engage group-based social support to increase individual capability, opportunity and motivation to change dietary behaviour and to increase MDS by $\geq 3$ points over 6 months (adoption phase) and 12 months (maintenance phase) in adults at high CVD risk.

The resulting intervention, delivered by trained 'lay' peers, was group-based and consisted of 11 group sessions delivered over 12 months, with 8 sessions delivered in an initial intensive phase (at baseline, 2 weeks, 4 weeks, 6 weeks, 2 months, 3 months, 4 months and 6 months), followed by 3 sessions during a maintenance phase (at months 8,10 and 12) as guided by qualitative work with our target population [44]. Each session lasted up to 2 hours and the format and content of sessions were designed to be interactive, non-directive and centred on discussion, with emphasis on shared experience and mutual reciprocity between peer supporters and group members for advice and support to achieve MD behaviour change.

Apart from an introductory meeting at baseline, subsequent group sessions had a similar format and theoretical basis as shown in Table 4. Each session had a dedicated discussion topic and included a brief (10-15 minutes) peer-delivered educational component designed to provide a focus for group discussion, as shown in Table 5 . The topics were selected to overcome identified barriers to adopting key MD food components in the target population such as increasing olive oil, nuts, fish and fruit and vegetables.

Written educational material (MD health and dietary education and MD pyramid) was provided at the beginning and further written resources were provided in staged format throughout the intervention (e.g. tips and suggestions, meal plans and seasonal recipe ideas) to overcome identified barriers and facilitate dietary behaviour change. MD educational resources aimed to create positive dietary beliefs and attitudes in the population by framing key dietary messages provided to group members in a helpful manner i.e. to 'replace,' 'substitute' or 'increase' specific food components, rather than to 'eat less,', 'reduce' or 'decrease' foods.

Observational learning was incorporated into the intervention and promoted via practical food demonstrations (using video and food tasting sessions) and through group discussion. To support diet behaviour change [36, 37], a personal planner was developed to encourage group members to record SMART dietary goals, self-monitor their progress, record challenges in making dietary changes and record personal clinical measures (anthropometrics, blood pressure). Group members were encouraged to make small, sustainable changes to their eating behaviour. They could share their goals, progress and challenges to attaining dietary goals with the group, who, in turn, were encouraged to help identify potential solutions via problem-solving discussion facilitated by group peer supporters.

A personal weigh-in and blood pressure measurement was made available for all group members at each session with biofeedback offered by peer supporters. At the end of each session, group member's summarised key 'take home' messages from the session and identified unresolved areas requiring further clarification. The research team provided written answers for any outstanding questions to peer supporters for feedback to the group at the start of the next meeting. Peer supporters also encouraged regular contact between group members beyond the scheduled group meetings (via telephone, text messaging and/or 
Table 4 Individual group session description and BCTs included in the peer support intervention

\begin{tabular}{|c|c|c|c|}
\hline Session component & Time allocated (min) & Description of session component & BCT(s) included \\
\hline $\begin{array}{l}\text { 1. Welcome and } \\
\text { attendance register }\end{array}$ & 5 & $\begin{array}{l}\text { Peer supporter keeps a record of attendance } \\
\text { for each session }\end{array}$ & - \\
\hline $\begin{array}{l}\text { 2. General progress } \\
\text { review }\end{array}$ & 10 & $\begin{array}{l}\text { Group discuss their progress in changing dietary } \\
\text { behaviour. Positive encouragement and support } \\
\text { between members is encouraged }\end{array}$ & Social support (unspecified) \\
\hline 3. Topic introduction & 25 & $\begin{array}{l}\text { Peer supporter introduces the group session topic. } \\
\text { The group share their experiences in relation to } \\
\text { the topic and identify the main challenges they } \\
\text { have or are likely to encounter in this area }\end{array}$ & $\begin{array}{l}\text { Social support (unspecified) } \\
\text { Provide normative behaviour about other's } \\
\text { behaviour }\end{array}$ \\
\hline $\begin{array}{l}\text { 4. Educational } \\
\text { demonstration }\end{array}$ & 15 & $\begin{array}{l}\text { Peer supporters deliver a short educational } \\
\text { demonstration such as a video, tasting session, } \\
\text { seasonal recipe ideas or a quiz }\end{array}$ & $\begin{array}{l}\text { Instruction on how, when and where to perform } \\
\text { the behaviour } \\
\text { Demonstrate the behaviour } \\
\text { Information about health consequences in general } \\
\text { Set graded tasks }\end{array}$ \\
\hline $\begin{array}{l}\text { 5. Supportive } \\
\text { discussion }\end{array}$ & 25 & $\begin{array}{l}\text { Group discussion centres on problem-solving } \\
\text { strategies to overcome identified challenges in } \\
\text { meeting SMART MD goals or in relation to } \\
\text { session topic }\end{array}$ & $\begin{array}{l}\text { Social support (unspecified) } \\
\text { Barrier identification/problem-solving }\end{array}$ \\
\hline $\begin{array}{l}\text { 6. Personal } \\
\text { action plan }\end{array}$ & 10 & $\begin{array}{l}\text { Group members are supported to set new or } \\
\text { review existing SMART MD goals }\end{array}$ & $\begin{array}{l}\text { Goal setting (behaviour) } \\
\text { Goal setting (outcome) } \\
\text { Action planning } \\
\text { Prompt self-monitoring of behaviour } \\
\text { Prompt review of behavioural goals }\end{array}$ \\
\hline $\begin{array}{l}\text { 7. Health } \\
\text { measurements }\end{array}$ & 10 & $\begin{array}{l}\text { Group members are offered an individual } \\
\text { measurement of blood pressure and weight. } \\
\text { Peer supporter offers personal feedback on } \\
\text { health measurements }\end{array}$ & $\begin{array}{l}\text { Biofeedback } \\
\text { Prompt self-monitoring of outcome }\end{array}$ \\
\hline 8. Key messages & 10 & $\begin{array}{l}\text { Group summarise key 'take home' messages } \\
\text { for the session }\end{array}$ & Social support (unspecified) \\
\hline $\begin{array}{l}\text { 9. Support between } \\
\text { sessions }\end{array}$ & 5 & $\begin{array}{l}\text { Peer supporters encourage ongoing } \\
\text { communication and contact between group } \\
\text { members outside the scheduled group sessions }\end{array}$ & Plan social support/social change \\
\hline 10. Next session & 5 & $\begin{array}{l}\text { Peer supporter provides an outline of the next } \\
\text { group session }\end{array}$ & - \\
\hline
\end{tabular}

SCT Social cognitive Theory, SSM Social Support Model, HBM Health Belief

face-to-face meetings) to promote social support and group cohesion.

\section{Logic model for the peer support MD intervention}

A logic model for the peer support MD intervention is shown in Figure 2 and outlines the intervention inputs, activities, components and proposed outcomes and potential contextual factors which may influence the peer support MD intervention mode of action and outcome measures. This provides a framework for evaluation of the peer support MD intervention to explore the extent to which social-cognitive factors (e.g. knowledge, attitudes, skills, self-efficacy and problem solving in relation to MD), in addition to factors relating to social support, mediate dietary change towards a MD.

\section{Discussion}

This paper describes the process of developing a theory-based, tailored peer support intervention to encourage dietary behaviour change towards a MD in adults at high CVD risk. Both MRC and BCW frameworks were valuable tools used successfully together to guide the intervention development process. The MRC framework was used systematically to identify the evidence base, develop theory and model processes and outcome, while the $\mathrm{BCW}$ was used to guide the theoretical basis of the peer support intervention, and tailor the content and format of the peer support intervention to the target population. Using a systematic development process optimises the feasibility of the peer support intervention to encourage MD behaviour change in the target group and minimises the risk of intervention failure. Applying the COM-B model raised our awareness of the significant number of barriers to perceived capability, opportunity and motivation to change dietary behaviour towards a MD in our non-Mediterranean population, but also provided guidance on the most appropriate methods needed to support dietary change. We believe that the behavioural approach to intervention design in the $\mathrm{BCW}$ allowed us to make more 
Table 5 Overview of the peer support group-based intervention content to encourage dietary change to a Mediterranean Diet

\begin{tabular}{|c|c|c|c|c|c|}
\hline Session & Delivered & Session topic & Session objectives & Core elements & $\begin{array}{l}\text { Resources delivered by } \\
\text { peer supporters }\end{array}$ \\
\hline 1 & FIRST SESSION & $\begin{array}{l}\text { CHANGING TO A } \\
\text { MEDITERRANEAN } \\
\text { DIET }\end{array}$ & $\begin{array}{l}\text { Increase awareness and knowledge of the type } \\
\text { and proportions of foods in the MD } \\
\text { Enable participants to set personal SMART MD } \\
\text { goals and to monitor their progress }\end{array}$ & $\begin{array}{l}\text { MD overview } \\
\text { SMART goals } \\
\text { Monitoring } \\
\text { progress }\end{array}$ & $\begin{array}{l}{ }^{*} \text { Mediterranean diet } \\
\text { pyramid poster }\end{array}$ \\
\hline 2 & WEEK 2 & $\begin{array}{l}\text { HEALTH BENEFITS } \\
\text { OF A MEDITERRANEAN } \\
\text { DIET }\end{array}$ & $\begin{array}{l}\text { Identify individual motivators for changing diet } \\
\text { towards MD } \\
\text { Learn about the health benefits of the MD and } \\
\text { discuss practical strategies to promote dietary } \\
\text { change }\end{array}$ & $\begin{array}{l}\text { MD and Health } \\
\text { Personal } \\
\text { Motivation } \\
\text { SMART goals } \\
\text { Monitoring } \\
\text { progress }\end{array}$ & $\begin{array}{l}\text { "Mediterranean diet } \\
\text { health benefits" Video } \\
\text { Recipe books, shopping } \\
\text { lists and meal plan for } \\
\text { the season (1) }\end{array}$ \\
\hline 3 & WEEK 4 & CHANGING FAT INTAKE & $\begin{array}{l}\text { Increase knowledge and awareness of the types } \\
\text { and proportions of beneficial fats in MD and } \\
\text { increase self-efficacy to change fat intake }\end{array}$ & $\begin{array}{l}\text { Changing fat } \\
\text { intake: Replacing } \\
\text { SFA with MUFA } \\
\text { Sources of MUFA }\end{array}$ & Oils and nuts to taste \\
\hline 4 & WEEK 6 & $\begin{array}{l}\text { SHOPPING FOR A } \\
\text { MEDITERRANEAN DIET }\end{array}$ & $\begin{array}{l}\text { Improve knowledge of MD foods and promote } \\
\text { self-efficacy to shop for MD on a budget }\end{array}$ & $\begin{array}{l}\text { Shopping for a } \\
\text { MD on a budget }\end{array}$ & $\begin{array}{l}\text { "Healthy Eating on a } \\
\text { budget" Video }\end{array}$ \\
\hline 5 & WEEK 8 & $\begin{array}{l}\text { ENJOY FRUIT AND } \\
\text { VEGETABLES }\end{array}$ & $\begin{array}{l}\text { Increase knowledge and awareness of FV as } \\
\text { components of MD and promote self-efficacy } \\
\text { to increase FV intake }\end{array}$ & $\begin{array}{l}\text { Sources and } \\
\text { portions of FV } \\
\text { and legumes }\end{array}$ & $\begin{array}{l}\text { "Fruit and Vegetables" } \\
\text { Video } \\
\text { Fruit and Vegetable } \\
\text { portion size guide }\end{array}$ \\
\hline 6 & MONTH 3 & $\begin{array}{l}\text { EATING A SEASONAL } \\
\text { MEDITERRANEAN DIET }\end{array}$ & $\begin{array}{l}\text { Increase awareness of seasonal MD recipes and } \\
\text { review personal MD goals in relation to seasonal } \\
\text { recipes }\end{array}$ & $\begin{array}{l}\text { MD for the } \\
\text { change in } \\
\text { season }\end{array}$ & $\begin{array}{l}\text { Recipe books, shopping } \\
\text { lists and meal plan for } \\
\text { the season ( } 2 \text { ) } \\
\text { Seasonal dish to taste }\end{array}$ \\
\hline 7 & MONTH 4 & $\begin{array}{l}\text { EATING MORE } \\
\text { WHOLEGRAIN }\end{array}$ & $\begin{array}{l}\text { Increase knowledge and awareness of wholegrain } \\
\text { intake as a component of MD and promote } \\
\text { self-efficacy to increase wholegrain intake }\end{array}$ & $\begin{array}{l}\text { Sources and } \\
\text { portions of } \\
\text { wholegrain }\end{array}$ & $\begin{array}{l}\text { Wholegrain food cards/ } \\
\text { quiz } \\
\text { Wholegrain portion size } \\
\text { guide }\end{array}$ \\
\hline 8 & MONTH 6 & $\begin{array}{l}\text { EATING A SEASONAL } \\
\text { MEDITERRANEAN DIET }\end{array}$ & $\begin{array}{l}\text { Increase awareness of seasonal MD recipes and } \\
\text { review personal MD goals in relation to seasonal } \\
\text { recipes }\end{array}$ & $\begin{array}{l}\text { MD for the } \\
\text { change in } \\
\text { season }\end{array}$ & $\begin{array}{l}\text { Recipe books, shopping } \\
\text { lists and meal plan for } \\
\text { the season (3) } \\
\text { Seasonal dish to taste }\end{array}$ \\
\hline 9 & MONTH 8 & $\begin{array}{l}\text { CONTINUING TO EAT } \\
\text { THE MEDITERRANEAN } \\
\text { WAY }\end{array}$ & $\begin{array}{l}\text { Review progress in achieving MD SMART goals } \\
\text { and promote on-going maintenance of MD } \\
\text { Promote maintenance of dietary changes }\end{array}$ & $\begin{array}{l}\text { Relapse } \\
\text { prevention }\end{array}$ & -- \\
\hline 10 & MONTH 10 & $\begin{array}{l}\text { EATING A SEASONAL } \\
\text { MEDITERRANEAN DIET }\end{array}$ & $\begin{array}{l}\text { Increase awareness of seasonal MD recipes and } \\
\text { review personal MD goals in relation to seasonal } \\
\text { recipes }\end{array}$ & $\begin{array}{l}\text { MD for the } \\
\text { change in } \\
\text { season }\end{array}$ & $\begin{array}{l}\text { Recipe books, shopping } \\
\text { lists and meal plan for } \\
\text { the season (4) } \\
\text { Seasonal dish to taste }\end{array}$ \\
\hline 11 & MONTH 12 & HOW HAVE WE DONE? & $\begin{array}{l}\text { Review progress in achieving MD SMART goals } \\
\text { and promote on-going maintenance of MD in } \\
\text { the future }\end{array}$ & $\begin{array}{l}\text { MD review } \\
\text { Review of } \\
\text { progress }\end{array}$ & -- \\
\hline
\end{tabular}

*This resource is used in each group session; MD Mediterranean Diet, SFA Saturated fatty acid, MUFA Monounsaturated fatty acid, EVOO Extra Virgin Olive Oil, RSO Rapeseed Oil, FV fruit and vegetables

informed decisions about which active ingredients to include in the intervention and helped us to find the right mix of strategies to drive behaviour change in the population. However, some decisions, particularly regarding which BCTs to include in the intervention, were pragmatic and taken on the basis of feasibility and resources available to deliver the intervention. Therefore, all the theoretical determinants of behaviour that were identified e.g. verbal persuasion and feedback on behaviour, may not be addressed in the developed peer support intervention but will be explored further during evaluation of the intervention. Furthermore, the formative research used to inform intervention development involved a population with relatively low MD adherence, and although we learned much about factors influencing adoption of new behaviours, little information was gleaned about longer-term maintenance of MD behaviour. As mentioned earlier, less is known about BCTs involved in sustained behaviour change, however coping and relapse prevention strategies are considered important. We felt problem-solving was a key BCT to increase motivation and self-efficacy for both adoption and maintenance of MD behaviours and important to include in the peer support intervention. Future 


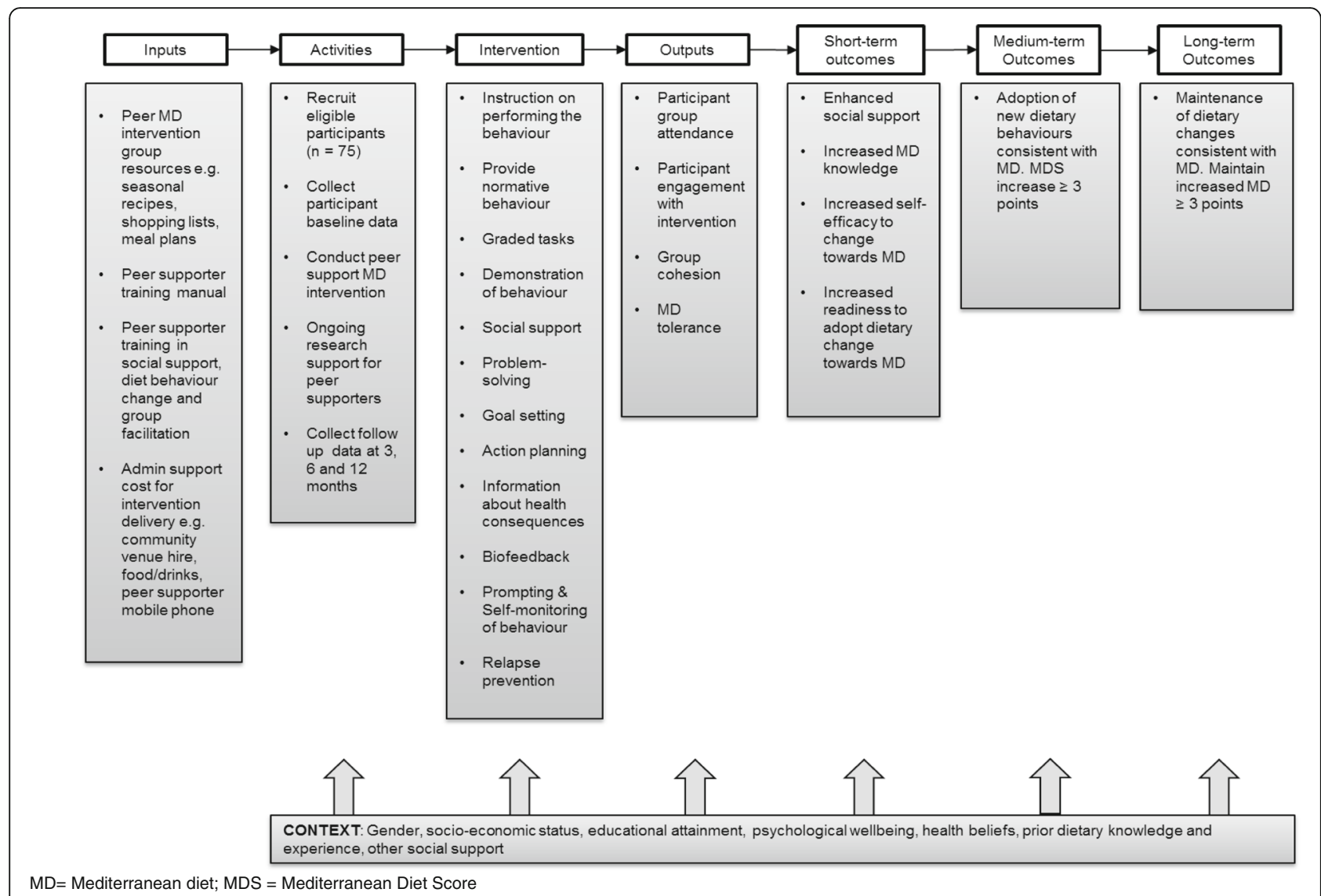

Fig. 2 Logic model for the peer support Mediterranean diet intervention

planned evaluations of the peer support intervention will aim to identify barriers and enablers to maintain MD behaviour change. We did not perform the 'policy option' step recommended in the BCW framework during the intervention development process. This component of the framework will be considered in more detail after the developed peer support intervention has undergone feasibility testing.

Clearly, there are a number of behaviours involved in adopting a MD and the next stage in the process will evaluate ease of adoption across the range of targeted behaviours and the acceptability of changing dietary behaviours in response to the peer support intervention. This approach will allow the intervention to be further adapted and tailored to the needs of the target population. A potential limitation to the peer support intervention is that it is designed to target only dietary behaviour change and does not consider broader lifestyle behaviours besides food consumption, such as physical activity and social interactions that define a Mediterranean lifestyle [45] and are also important modifiable behaviours for CVD prevention [46]

A major strength of the study is that a systematic approach was applied to develop the peer support intervention. Although the process was time intensive taking almost one year to complete, it provides a coherent basis for process evaluation of the intervention. The next stage in the MRC framework recommends pilot testing of the developed intervention. We plan to test the feasibility of the peer support intervention to encourage dietary behaviour change towards a MD in the target population, in comparison to both an intensive support intervention already shown to be effective [2], and a minimal support intervention. The protocol for this pilot RCT is being reported elsewhere and will define randomisation, recruitment strategies, outcome measures and analysis plan.

\section{Conclusions}

In conclusion, the staged $\mathrm{MRC}$ and $\mathrm{BCW}$ process provided a systematic and complementary approach to developing a theory-based peer support intervention to encourage dietary behaviour change towards a MD in adults at high CVD risk. The next step is to evaluate the feasibility of the peer support intervention to, ultimately, inform the design of a larger scale RCT where the efficacy and cost-effectiveness of the peer support intervention will be tested. 


\section{Abbreviations}

BCW: Behaviour Change Wheel; BCTT: Behaviour Change Taxonomy; CALORE: Coventry, Aberdeen, and London-Refined taxonomy; COM-B: Capability, Opportunity, Motivation - Behaviour; CVD: Cardiovascular disease; HBM: Health Belief Model; MD: Mediterranean Diet; MDS: Mediterranean Diet Score; MRC: Medical Research Council; RCT: Randomised Controlled Trial; SCT: Social Cognitive Theory; T2DM: Type 2 Diabetes Mellitus

\section{Acknowledgements}

The authors wish to express thanks to the individuals who participated in the qualitative research for their valuable contribution to the development of the peer support intervention and to the Community Development and Health Network and the Northern Ireland Clinical Research Network (Primary Care) for their help with participant recruitment.

\section{Funding}

This work was funded by the National Prevention Research Initiative (NPRl; https://mrc.ukri.org/research/initiatives/prevention-research/nationalprevention-research-initiative-npri/). NPRI funding partners were (in alphabetical order): Alzheimer's Research Trust; Alzheimer's Society; Biotechnology and Biological Sciences Research Council; British Heart Foundation; Cancer Research UK; Chief Scientist Office, Scottish Government Health Directorate; Department of Health; Diabetes UK; Economic and Social Research Council; Health and Social Care Research and Development Division of the Public Health Agency (HSC R\&D Division); Medical Research Council; The Stroke Association; Wellcome Trust; Welsh Assembly Government; and World Cancer Research Fund. The funding source was not involved in the research process.

\section{Availability of data and materials}

The datasets used and/or analysed during the current study are available from the corresponding author on reasonable request.

\section{Authors' contributions}

CME, contributed to the design, data acquisition, analysis and interpretation, drafting and editing the manuscript and final approval of manuscript. SEM, contributed to data acquisition, interpretation of data, editing the manuscript and revising it for intellectual content and final approval of manuscript. KMA contributed to the interpretation of data, editing the manuscript and revising it for intellectual content and final approval of manuscript. MEC contributed to interpretation of data, editing the manuscript and revising it for intellectual content and final approval of manuscript. CE contributed to interpretation of data, editing the manuscript and revising it for intellectual content and final approval of manuscript. FK contributed to interpretation of data, editing the manuscript and revising it for intellectual content and final approval of manuscript. LP contributed to qualitative data analysis and interpretation, editing and revising the manuscript for intellectual content and final approval of manuscript. ISY contributed to interpretation of data, editing the manuscript and revising it for intellectual content and final approval of manuscript. MMK contributed to the design, data acquisition, analysis and interpretation, editing the the manuscript and revising it critically for intellectual content and final approval of manuscript. JWV contributed to overall study supervision, conception, design, data interpretation and analysis, editing the manuscript and revising it for intellectual content and and final approval of manuscript.

\section{Ethics approval and consent to participate}

Ethical approval for the qualitative research was granted by the Office for Research Ethics Committees, Northern Ireland, (REC1, 12/NI/0043) and written informed consent was obtained from all participants.

\section{Consent for publication}

Not applicable

\section{Competing interests}

The authors declare they have no competing interests.

\section{Publisher's Note}

Springer Nature remains neutral with regard to jurisdictional claims in published maps and institutional affiliations.

\section{Author details}

'Centre for Public Health, Queen's University Belfast, Grosvenor Road, Belfast BT12 6BJ, UK. ${ }^{2}$ Research Centre for Behaviour Change, Department of Psychology, Faculty of Science and Technology, Bournemouth University, Fern Barrow, Talbot Campus, Bournemouth BH12 5BB, UK. ${ }^{3}$ UK Clinical Research Collaboration, Centre of Excellence for Public Health, Queens University Belfast, Grosvenor Road, Belfast BT12 6BJ, UK.

Received: 9 May 2018 Accepted: 10 October 2018

Published online: 22 October 2018

\section{References}

1. Mente A, de Koning L, Shannon HS, Anand SS. A systematic review of the evidence supporting a causal link between dietary factors and coronary heart disease. Arch Intern Med. 2009:169:659-69.

2. Estruch R, Ros E, Salas-Salvadó J, Covas MI, Corella D, Arós F, et al. Primary Prevention of Cardiovascular Disease with a Mediterranean diet. NEJM. 2013; 368:1279-90.

3. Salas-Salvadó J, Bulló M, Estruch R, Ros E, Covas MI, Ibarrola-Jurado N, et al. Prevention of diabetes with Mediterranean diets: a subgroup analysis of a randomized trial. Ann Intern Med. 2014;160:1-10.

4. Dennis CL. Peer support within a health care context: a concept analysis. Int J Nurs Stud. 2003:40:321-32.

5. Toobert DJ, Strycker LA, Glasgow RE, Barrera M Jr, Angell K. Effects of the mediterranean lifestyle program on multiple risk behaviors and psychosocial outcomes among women at risk for heart disease. Ann Behav Med. 2005:29: 128-37.

6. Shepherd J, Harden A, Rees R, Brunton G, Garcia J, Oliver S, Oakley A. Young people and healthy eating: a systematic review of research on barriers and facilitators. Health Educ Res. 2006;21:239-57.

7. Spahn JM, Reeves RS, Keim KS, Laquatra I, Kellogg M, Jortberg B, Clark NA. State of the evidence regarding behavior change theories and strategies in nutrition counseling to facilitate health and food behavior change. J Am Diet Assoc. 2010;110:879-91.

8. Campbell NC, Murray E, Darbyshire J, Emery J, Farmer A, Griffiths F, et al. Designing and evaluating complex interventions to improve health care. BMJ. 2007:334:455-9.

9. Jepson RG, Harris FM, Platt S, Tannahill C. The effectiveness of interventions to change six health behaviours: a review of reviews. BMC Public Health. 2010 Sep;10:538.

10. French SD, Green SE, O'Connor DA, McKenzie JE, Francis JJ, Michie S, et al. Developing theory-informed behaviour change interventions to implement evidence into practice: a systematic approach using the Theoretical Domains Framework. Implement Sci. 2012;7:38.

11. Craig P, Dieppe P, Macintyre S, Michie S, Nazareth I, Petticrew M; Medical Research Council Guidance. Developing and evaluating complex interventions: the new Medical Research Council guidance. BMJ. 2008;337:a1655.

12. Datta J, Petticrew M. Challenges to evaluating complex interventions: a content analysis of published papers. BMC Public Health. 2013;13:568.

13. Faes MC, Reelick MF, Esselink RA, Rikkert MG. Developing and evaluating complex healthcare interventions in geriatrics: the use of the medical research council framework exemplified on a complex fall prevention intervention. J Am Geriatr Soc. 2010:58:2212-21.

14. Goldstein LH, Mellers JD, Landau S, Stone J, Carson A, Medford N, et al. COgnitive behavioural therapy vs standardised medical care for adults with Dissociative non-Epileptic Seizures (CODES): a multicentre randomised controlled trial protocol. BMC Neurol. 2015:15:98.

15. Troughton J, Chatterjee S, Hill SE, Daly H, Martin Stacey L, et al. Development of a lifestyle intervention using the MRC framework for diabetes prevention in people with impaired glucose regulation. J Public Health (Oxf). 2015; pii: fdv110.

16. Lakshman R, Griffin S, Hardeman W, Schiff A, Kinmonth AL, Ong KK. Using the Medical Research Council framework for the development and evaluation of complex interventions in a theory-based infant feeding intervention to prevent childhood obesity: the baby milk intervention and trial. J Obes. 2014:646504.

17. Bartholomew LK, Mullen PD. Five roles for using theory and evidence in the design and testing of behavior change interventions. J Public Health Dent. 2011;71(Suppl 1):S20-33.

18. Green L, Kreuter M. Health program planning: An educational and ecological approach. 4th ed. New York: McGraw-Hill; 2005. 
19. Michie S, van Stralen MM, West R. The behaviour change wheel: a new method for characterising and designing behaviour change interventions. Implement Sci. 2011;6:42

20. Michie S, Atkins L, West R. The Behaviour Change Wheel A Guide To Designing Interventions. London: Silverback Publishing; 2014.

21. Atkins $L$, Michie $S$. Designing interventions to change eating behaviours. Proc Nutr Soc. 2015;74:164-70.

22. de Lorgeril M, Salen P, Martin JL, Monjaud I, Delaye J, Mamelle N. Mediterranean diet, traditional risk factors, and the rate of cardiovascular complications after myocardial infarction: final report of the Lyon Diet Heart Study. Circulation. 1999;99:779-85.

23. Michie S, Richardson M, Johnston M, Abraham C, Francis J, Hardeman W, et al. The behavior change technique taxonomy ( $v 1)$ of 93 hierarchically clustered techniques: building an international consensus for the reporting of behavior change interventions. Ann Behav Med. 2013;46:81-95.

24. Michie S, Ashford S, Sniehotta FF, Dombrowski SU, Bishop A, French DP. A refined taxonomy of behaviour change techniques to help people change their physical activity and healthy eating behaviours: The CALO-RE taxonomy. Psychol Health. 2011;26:1479-98.

25. Noah A, Truswell AS. There are many Mediterranean diets. Asia Pac J Clin Nutr. 2001;10:2-9.

26. Sofi F, Macchi C, Abbate R, Gensini GF, Casini A. Mediterranean diet and health status: an updated meta-analysis and a proposal for a literaturebased adherence score. Public Health Nutr. 2014;17:2769-82.

27. Logan KJ, Woodside JV, Young IS, McKinley MC, Perkins-Porras L, McKeown PP. Adoption and maintenance of a Mediterranean diet in patients with coronary heart disease from a Northern European population: a pilot randomised trial of different methods of delivering Mediterranean diet advice. J Hum Nutr Diet. 2010;23:30-7.

28. Moore SE, McEvoy CT, Prior L, Lawton JA, Kee F, Cupples M, et al. Barriers to adopting a Mediterranean diet in Northern European adults at high risk of developing Cardiovascular disease. J Hum Nutr Diet. 2017. https://doi.org/ 10.1111/jhn.12523.

29. Cohen S, Gottlieb B, Underwood L. Social relationships and health. In: Cohen S, Underwood L, Gottlieb B, editors. Social support measurement and intervention. New York: Oxford University Press; 2000. p. 3-28.

30. Bandura A. Health promotion from the perspective of social cognitive theory. Psychol Health. 1998;13:623-49.

31. Steptoe A, Perkins-Porras L, Rink E, Hilton S, Cappuccio FP. Psychological and social predictors of changes in fruit and vegetable consumption over 12 months following behavioral and nutrition education counselling. Health Psychol. 2004;23:574-81.

32. Anderson ES, Winett RA, Wojcik JR, Williams DM. Social cognitive mediators of change in a group randomized nutrition and physical activity intervention: social support, self-efficacy, outcome expectations and selfregulation in the guide-to-health trial. J Health Psychol. 2010;15:21-32.

33. Anderson ES, Winett RA, Wojcik JR. Self-regulation, self-efficacy, outcome expectations, and social support: social cognitive theory and nutrition behavior. Ann Behav Med. 2007;34:304-12.

34. Glanz K, Rimer BK, Lewis FM. Health Behavior and Health Education. Theory, Research and Practice. San Francisco: Wiley \& Sons; 2002.

35. Funnell MM. Peer-based behavioural strategies to improve chronic disease self-management and clinical outcomes: evidence, logistics, evaluation considerations and needs for future research. Fam Pract. 2010;27:117-22.

36. Greaves CJ, Sheppard KE, Abraham C, Hardeman W, Roden M, Evans PH, Schwarz P, IMAGE Study Group. Systematic review of reviews of intervention components associated with increased effectiveness in dietary and physical activity interventions. BMC Public Health. 2011;11:119.

37. Lara J, Evans EH, O'Brien N, Moynihan PJ, Meyer TD, Adamson AJ, et al. Association of behaviour change techniques with effectiveness of dietary interventions among adults of retirement age: a systematic review and meta-analysis of randomised controlled trials. BMC Med. 2014;12:177.

38. Samdal GB, Eide GE, Barth T, Williams G, Meland E. Effective behaviour change techniques for physical activity and healthy eating in overweight and obese adults; systematic review and meta-regression analyses. Int J Behav Nutr Phys Act. 2017;14:42.

39. Collins RL. Relapse prevention for eating disorders and obesity. In: Marlatt GA, Donovan DA, editors. Relapse prevention: Maintenance strategies in the treatment of addictive behaviors. New York: Guilford Press; 2005. p. 305-33.

40. Dale JR, Williams SM, Bowyer V. What is the effect of peer support on diabetes outcomes in adults? A systematic review. Diabet Med. 2012;29:1361-77.
41. Gibson S, Food Standards Agency. Peer-led approaches to dietary change: report of the Food Standards Agency seminar held on 19 July 2006. Public Health Nutr. 2007;10:980-8.

42. Murphy CA, Cupples ME, Percy A, Halliday HL, Stewart MC. Peer-mentoring for first-time mothers from areas of socio-economic disadvantage: a qualitative study within a randomised controlled trial. BMC Health Serv Res. 2008;8:46.

43. Heisler M. Overview of peer support models to improve diabetes selfmanagement and clinical outcomes. Diabetes Spectrum. 2007;20:214-21.

44. Erwin CM, McEvoy CT, Moore SE, Prior L, Lawton J, Kee F, et al. A qualitative analysis exploring preferred methods of peer support to encourage adherence to a Mediterranean diet in a Northern European population at high risk of cardiovascular disease. BMC Public Health. 2018;18:213. https:// doi.org/10.1186/s12889-018-5078-5.

45. Bach-Faig A, Berry EM, Lairon D, Reguant J, Trichopoulou A, Dernini S, et al. Mediterranean Diet Foundation Expert Group. Mediterranean diet pyramid today. Science and cultural updates. Public Health Nutr. 2011;14:2274-84.

46. Lloyd-Jones DL, Hong Y, Labarthe D, et al. Defining and Setting National Goals for Cardiovascular Health Promotion and Disease Reduction The American Heart Association's Strategic Impact Goal Through 2020 and Beyond. Circulation. 2010;121:586-613.

\section{Ready to submit your research? Choose BMC and benefit from:}

- fast, convenient online submission

- thorough peer review by experienced researchers in your field

- rapid publication on acceptance

- support for research data, including large and complex data types

- gold Open Access which fosters wider collaboration and increased citations

- maximum visibility for your research: over $100 \mathrm{M}$ website views per year

At $\mathrm{BMC}$, research is always in progress.

Learn more biomedcentral.com/submissions 